\title{
Synthetic peptides from two Pf sporozoite invasion-associated proteins specifically interact with HeLa and HepG2 cells
}

\author{
Gabriela Arévalo-Pinzón $^{\mathrm{a}, \mathrm{b}}$, Hernando Curtidor ${ }^{\mathrm{a}, \mathrm{b}}$, Marina Muñoz ${ }^{\mathrm{a}, \mathrm{b}}$, Manuel A. Patarroyo ${ }^{\mathrm{a}, \mathrm{b}}$, \\ Manuel E. Patarroyo ${ }^{\mathrm{a}, \mathrm{c}, *}$
}

a Fundación Instituto de Inmunología de Colombia (FIDIC), Carrera 50 \# 26-20, Bogotá, Colombia

${ }^{\mathrm{b}}$ Universidad del Rosario, Calle 14 \# 6-25, Bogotá, Colombia

c Universidad Nacional de Colombia, Carrera 45 \# 26-85, Bogotá, Colombia

\section{A R T I C L E I N F O}

\section{Article history:}

Received 16 July 2011

Received in revised form 9 August 2011

Accepted 9 August 2011

Available online 16 August 2011

\section{Keywords:}

Cell-traversal

High-activity binding peptide

Antimalarial vaccine

Plasmodium falciparum

Sporozoite invasion

\begin{abstract}
A B S T R A C T
Two recently described molecules have been associated with sporozoite traversal ability and hepatocyte entry: sporozoite invasion-associated proteins (SIAP)-1 and -2 . The HeLa and HepG2 cell binding ability of synthetic peptides spanning the whole SIAP-1 and -2 sequences has been studied in the search for identifying these proteins' functionally active specific regions. Twelve HepG-2 and seventeen HeLa cell high-activity binding peptides (HABPs) have been identified in SIAP-1, 8 of them having high specific binding affinity for both cell lines. Four HepG2 HABPs and two HeLa HABPs have been identified in SIAP-2, one of them interacting with both HeLa and HepG2 cells. SIAP-1 and SIAP-2 HABPs bound specifically and saturably to heparin sulfate and chondroitin sulfate-type membrane receptors on host cells. Circular dichroism assays have shown high $\alpha$-helix content in SIAP-1 and SIAP-2 HABP secondary structure. Immunofluorescence analysis has revealed that specific peptides against SIAP proteins are highly immunogenic in mice and that anti-SIAP-1 and -2 antibodies recognize the native protein in Plasmodium falciparum sporozoites. Polymorphism studies have shown that a most SIAP- 1 and -2 HABPs are conserved among $P$. falciparum strains. Our results have suggested that SIAP- 1 and -2 participate in host-pathogen interactions during cell-traversal and hepatocyte invasion and highlighted the relevance of the ongoing identification and study of potentially new molecules when designing a fully protective antimalarial vaccine.
\end{abstract}

(C) 2011 Elsevier Inc. All rights reserved.

\section{Introduction}

Plasmodium falciparum malaria is still one of the major health problems worldwide, highlighting the need for developing wholly effective immunotherapeutic and immunoprophylactic methods such as vaccines; efforts have been directed at identifying new parasite-derived molecules as potential subunit-based antimalarial vaccine candidates.

$P$. falciparum malaria starts in humans when they are bitten by an infected Anopheles female mosquito; such bite injects 100-1000 parasite larval-like forms known as sporozoites into the skin. These initial invasive forms travel through the bloodstream to the liver where, once the parasite has crossed the liver sinusoidal wall, it recognizes and invades hepatic cells [19,36]. Transcriptome and up-regulation in gene expression analysis during this stage have recently revealed a new set of sporozoite proteins as attractive

\footnotetext{
* Corresponding author at: Fundación Instituto de Inmunología de Colombia, Carrera 50 \# 26-20, Bogotá, Colombia. Tel.: +57 1 4815219; fax: +57 14815269.

E-mail address: mepatarr@mail.com (M.E. Patarroyo).
}

prospects for functional and immunological studies [18,34]. Among these, two new proteins have been described as being up-regulated at $37^{\circ} \mathrm{C}$ and possibly involved in sporozoite cell-traversal and hepatocyte invasion: sporozoite-invasion associated proteins (SIAP)-1 and -2 .

The $113 \mathrm{kDa}$ SIAP-1/S5 [18,34] and $45 \mathrm{kDa}$ SIAP-2 [34] proteins are encoded by a single exon and represent genes expressed in sporozoites containing a predicted signal peptide. Immunofluorescence assays (IFA) have confirmed the presence of these two surface proteins having a similar localization to that observed for the circumsporozoite protein (CSP). Western blot has also revealed temperature-dependent processing for SIAP-1, being possibly cleaved in $37^{\circ} \mathrm{C}$-incubated sporozoites into a $75 \mathrm{kDa}$ cleavage product, reminiscent of apical membrane antigen (AMA)-1 and the thrombospondin related adhesion protein (TRAP) processing [34,35]. siap-1 gene disruption has revealed that this process does not affect sporozoite formation but that it can cause a partial defect in sporozoite output from oocytes, migration to the salivary glands and infection of a mammalian host [9], suggesting SIAP-1's multi-stage functional role during Plasmodium transmission within its invertebrate and vertebrate hosts. By contrast, anti-SIAP-2 
antibodies have recognized a $75 \mathrm{kDa}$ polypeptide having a higher molecular weight than its $45 \mathrm{kDa}$ predicted molecular mass, suggesting in vivo post-translational modifications to the original protein [34]. Interestingly, anti-SIAP-1 and SIAP-2 antibodies have inhibited both sporozoite cell-crossing and hepatocyte invasion, having a more significant in vitro effect on parasite migration through HeLa cells for both proteins, this being comparable to the inhibition obtained with anti-CSP antibodies [34].

Fine SIAP-1 and SIAP-2 binding profiles have been constructed as part of our ongoing efforts using non-overlapping sequential 20mer-long synthetic peptides covering the complete length of these two proteins in highly robust specific and sensitive binding assays with HeLa (epidermis-derived) and HepG2 (hepatocyte-derived) cells. The high-activity binding peptides (HABPs) identified here have been analyzed by saturation assays, enzyme treatment of host cells regarding peptide binding and secondary structure elucidation in circular dichroism (CD) spectra. The results have indicated that SIAP-1 and -2 HABPs are attractive targets for determining their immunological properties in the Aotus monkey experimental animal model.

\section{Materials and methods}

\subsection{HepG2 and HeLa cell culture}

These cells were cultured as thoroughly described in Curtidor et al. [8].

\subsection{SIAP-1 and SIAP-2 peptide synthesis}

The $t$-Boc solid phase peptide synthesis strategy was used to reproduce the whole $P$. falciparum 3D7 SIAP-1 (PFD0425w) and SIAP-2 (PF08_0005) strain sequences in 20-mer-long nonoverlapping peptides [13]. Our institute's serial system was used to number all sequences (Fig. 1). Polymer peptides were synthesized to produce anti-SIAP-1 and SIAP-2 by adding CG at the N-terminus and $\mathrm{GC}$ at the $\mathrm{C}$-terminus to allow oxidative polymerization, as previously described (Fig. 1, shaded sequences).

\subsection{Radiolabeling and HeLa and HepG2 binding assays}

SIAP-1 and SIAP-2-derived peptides were incubated with $5 \mu \mathrm{L}$ $\mathrm{Na}^{125} \mathrm{I}(100 \mathrm{mCi} / \mathrm{mL}$, MP Biomedicals) and $15 \mu \mathrm{L}$ chloramine$\mathrm{T}(2.75 \mathrm{mg} / \mathrm{mL})$ for $15 \mathrm{~min}[8,11,33]$. Next, $15 \mu \mathrm{L}$ of sodium metabisulfite $(2.25 \mathrm{mg} / \mathrm{mL})$ was added; radiolabeled peptides were then purified on a Sephadex G-10 column and analyzed in an automatic gamma counter (Gamma Counter Cobra II). Radiolabeled peptides were used in HepG2 and HeLa cell binding assays according to previously described protocols $[8,11]$.

Specific binding was defined as the amount (\%) of peptide (pmol) that specifically bound to RBCs per amount of added peptide ( $\mathrm{pmol}$ ). The binding curve was obtained by calculating the difference between total binding (binding in the absence of non-radiolabeled peptide) and unspecific binding (binding in the presence of nonradiolabeled peptide). Based on these data, peptides having a $\geq 0.02$ specific binding curve slope were considered to be HABPs, according to previously reported criteria establishing that a HABP recognizes more than 2000 binding sites per cell, having nanomolar dissociation constants $\left(K_{d}\right)[8,11,23,39]$. Some SIAP- 1 and SIAP2 HABPs so identified were analyzed in modified binding assays, spanning a wider range of radiolabeled peptide concentrations (0-3400 nM) to determine their binding kinetic constants.

\subsection{Effect of enzyme treatment on HABP binding}

Cell lines were suspended in HBS buffer and independently treated for $1 \mathrm{~h}$ at $37^{\circ} \mathrm{C}$ with $500 \mu \mathrm{U} / \mathrm{mL}$ heparinase I (HI; CAS 9025-39-2, Sigma), heparinase II (HII; CAS 149371-12-0, Sigma), chondroitinase AC (CAC; CAS 9047-57-8, Sigma) and chondroitinase ABC (CABC; CAS 9024-13-9, Sigma). Treated cells were then washed and assessed as in conventional binding assays, using untreated cells as positive control.

\subsection{HABPs' secondary structure analysis}

SIAP-1 and SIAP-2 HABPs' secondary structure was analyzed by circular dichroism (CD). All spectra were acquired on Jasco J-810 (JASCO Inc.) equipment by averaging three sweeps taken at $20 \mathrm{~nm} / \mathrm{min}$. The data was then processed by Spectra Manager software and analyzed with CONTINLL, SELCON, and CDSSTR deconvolution software [37].

\subsection{Anti-SIAP-1 and SIAP-2 antibody production}

SIAP-1 and SIAP-2 sequences were analyzed using BcePred (http://www.imtech.res.in/raghava/bcepred/) and BCPREDS (http://ailab.cs.iastate.edu/bcpred/index.html) prediction servers to identify specific B-cell epitopes. BALB/c mice were intraperitoneally (ip) immunized with a mixture containing $75 \mu \mathrm{g}$ of each SIAP-1 and SIAP-2 polymer peptide emulsified with Freund's complete adjuvant (FCA) on day 0 . Mice received booster doses emulsified in Freund's incomplete adjuvant (FIA) on days 30, 45, 60 and 75. Immunization and bleeding were carried out on day 90 and serum samples were collected for further analysis. Animals were kept according to the guidelines established by the Colombian Ministry of Health for handling live animals for research or experimental purposes.

\subsection{Indirect immunofluorescence assays}

Anti-SIAP-1 and -2 antibody reactivity was characterized by immunofluorescence on P. falciparum sporozoite plates (3D7 strain) kindly provided by Dr. Patricia de la Vega (Naval Institute Bethesda, MD, USA). Parasites air-fixed on slides were blocked for $10 \mathrm{~min}$ with $1 \%$ skimmed milk and incubated for 30 min with mouse immune serum at 1:20 dilution. Slides were visualized under a fluorescence microscopy using Fluorescein (FITC) anti-mouse IgG (Vector Laboratories) diluted 1:100. Pre-immune mouse sera were used as negative controls.

\subsection{P. falciparum genomic DNA extraction and purification}

$200 \mu \mathrm{L}$ of erythrocytes parasitized with the P. falciparum FCB-2, FVO and PAS-2 strains (30\% parasitemia) were obtained from an asynchronous culture maintained as described elsewhere [38] and lysed using $0.2 \%$ saponin. Genomic DNA (gDNA) from each strain isolate was extracted using an UltraClean DNA blood isolation kit (MO BIO, Carlsbad, CA).

\subsection{PCR amplification}

The genes encoding SIAP-1 and SIAP-2 in the P. falciparum 3D7 reference strain (GenBank access number PFD0425w and PF08_0005, respectively) were analyzed to design specific primer sets for amplifying and sequencing the regions encoding SIAP-1 and SIAP-2 HABPs. Three primer sets were designed for SIAP1 and one for SIAP-2 using Gene Runner v3.05. These primer sets' sequences were SIAP1-F1 (5'-AGGCTTTGTTGCTTTGCTG$\left.3^{\prime}\right)$ and SIAP1-R1 (5'-AATTAACTTCTTCACATACTTC-3') for 

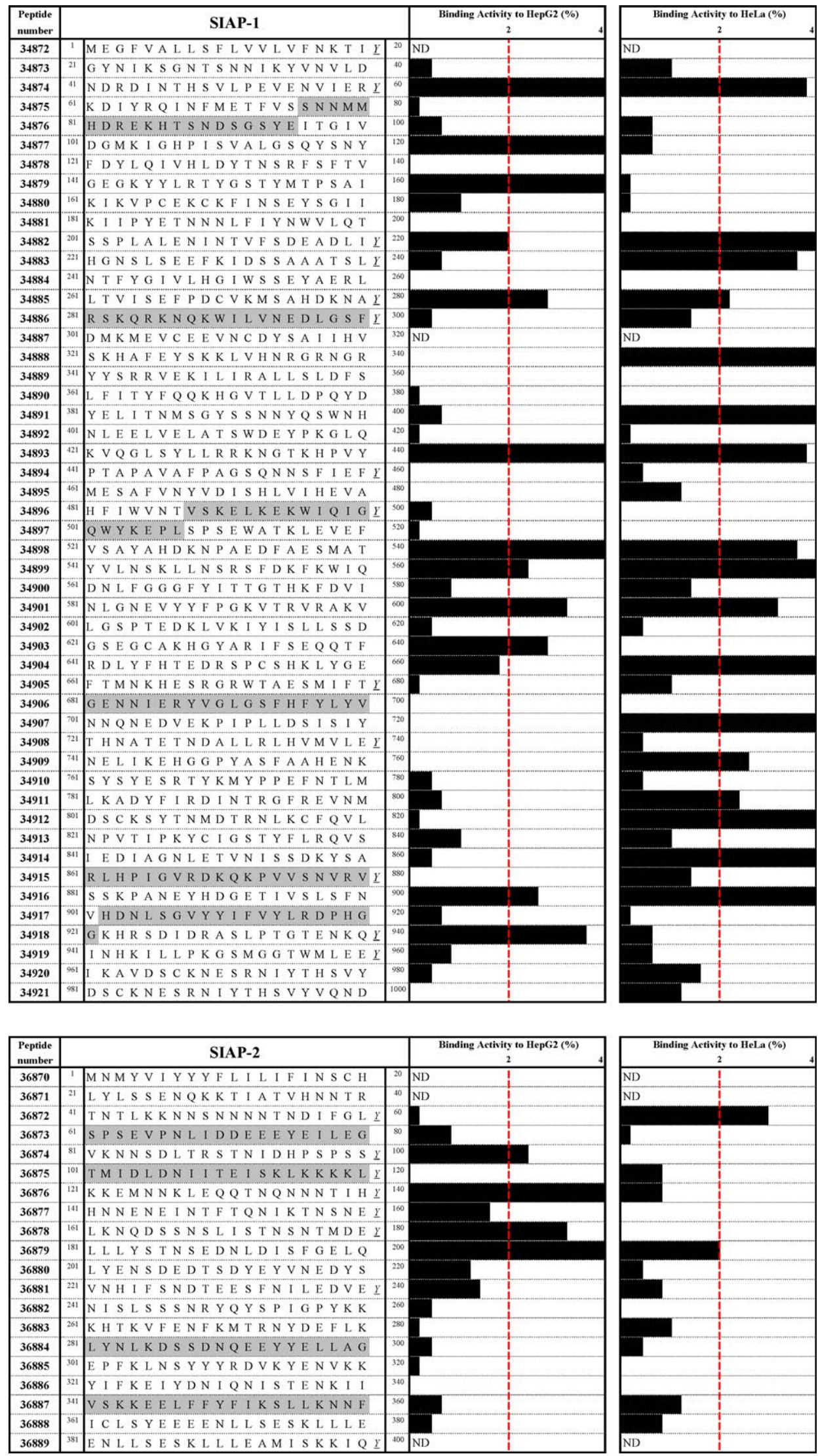

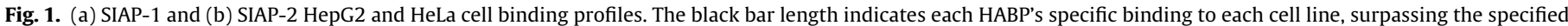

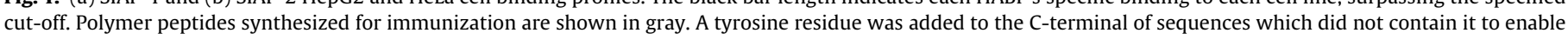
them to be radiolabeled. ND, not determined. 
amplifying the region encoding HABPs 34874-34885. SIAP1-F2 (5'-AAATGGAAGTATGTGAAGAAG-3') and SIAP1-R2 $\left(5^{\prime}\right.$-TAGCACAACCTTCAGAACC-3') were used for amplifying the region encoding HABPs 34888-34901 and SIAP1-F3 $\left(5^{\prime}\right.$-TCCGACTGAAGATAAATTAGT-3') and SIAP1-R3 (5'ATGTGGATCTCTTAGATATAC-3') for amplifying the region encoding HABPs 34903-34916. The only primer set for SIAP2 was SIAP2-F (5'-CCATCTATACTTATCTTCCG-3') and SIAP2-R (5'-ATATTGATATCTATTACTTGATG-3') amplifying the region encoding HABPs 36872-36879. The region encoding $P$. falciparum integral membrane protein Pf25-IMP HABP 33577 amplified using DIR1 and REV1 primers was included as positive PCR control [7].

DNA regions were amplified in $50 \mu \mathrm{L}$ amplification reaction mixture containing 1.25 U BioTaqTM DNA polymerase (Bioline), $1 \times$ Taq polymerase reaction buffer, $2.5 \mathrm{mM} \mathrm{MgCl}_{2}, 0.25 \mathrm{mM}$ dNTPs and $1 \mu \mathrm{M}$ of each primer. The following thermocycling profile was used for all primer sets: an initial denaturing step at $95^{\circ} \mathrm{C}$ for $5 \mathrm{~min}$, followed by 35 cycles consisting of $1 \mathrm{~min}$ annealing at $56^{\circ} \mathrm{C}, 1 \mathrm{~min}$ extension step at $72{ }^{\circ} \mathrm{C}$ and $1 \mathrm{~min}$ denaturing at $95^{\circ} \mathrm{C}$, followed by a final extension step at $72^{\circ} \mathrm{C}$ for $5 \mathrm{~min}$. The same reaction conditions using DNase- and RNase-free water instead of DNA were assayed as negative control. Amplification products were purified using a Wizard PCR preps kit (Promega) and were sequenced using their corresponding forward and reverse primers.

\section{Results and discussion}

The circumsporozoite protein (CSP) and the thrombospondinrelated anonymous protein (TRAP) represent the most widely studied antigens to date among the most important pre-erythrocyte vaccine candidates $[1-3,30,31,36]$. Several $P$. falciparum proteins have been widely related to liver sinusoidal cell-traversal, such as the cell traversal protein for ookinetes and sporozoites (CelTOS) [20], sporozoite micronemal proteins essential for cell traversal, SPECT-1 and SPECT-2 [14,16,17] and the TRAP-like protein (TLP) [24]. Other antigens have been associated with hepatocyte invasion and parasite development, including the thrombospondin-related sporozoite protein (TRSP) [18,22], apical membrane antigen-1 (AMA-1) [35] and Cys $_{6}$ family protein members P36 and P52/P36p $[15,40]$. However, a more significant number of antigens must be studied due to Plasmodium parasites' great complexity and the alternative pathways used as invasion and immune evasion mechanisms for them to be evaluated as antimalarial vaccine candidates $[12,28,32]$.

\subsection{SIAP-1 and SIAP-2 regions specifically interact with HeLa and HepG2 cell lines}

In line with the above, fine HeLa and HepG2 cell line binding profiles have thus been constructed for these proteins using a highly specific, sensitive and robust receptor-ligand methodology, within the framework of a logical and rational strategy for identifying specific regions involved in SIAP-1 and SIAP-2 interactions with mammalian cells which could be participating in cell traversal and hepatocyte invasion $[12,28,32]$.

Twelve SIAP-1-derived HABPs have been identified which were distributed throughout this protein's whole sequence (Fig. 1). Likewise, 17 HABPs representing around 34\% of SIAP1 , bound to HeLa cells with a similar distribution pattern to that identified for HepG2 cells (Fig. 1 and Table 1). Interestingly, SIAP-1 HABPs 34874 ( ${ }^{41}$ NDRDINTHSVLPEVENVIER $\left.{ }^{60} Y\right)$, 34882 ( ${ }^{201}$ SSPLALENINTVFSDEADLI $\left.{ }^{220} Y\right), 34885$ ( ${ }^{261}$ LTVISEFPDCVKMSAHDKNA ${ }^{280} Y$ ), $34893\left({ }^{421}\right.$ KVQGLSYLLRRKNGTKHPVY $\left.^{440}\right)$, 34898 ( ${ }^{521}$ VSAYAHDKNPAEDFAESMAT $\left.{ }^{540}\right), 34899$ ( ${ }^{541}$ YVLNSKLLNSRSFDKFKWIQ ${ }^{560}$ ), 34901 ( ${ }^{581}$ NLGNEVYYFPGKVTRVRAKV $^{600}$ )
Table 1

Determining binding constants $\left(K_{d}\right)$, Hill coefficients $\left(n_{\mathrm{H}}\right)$ and binding sites per cell (BSC) for SIAP-1 and -2 HABPs.

\begin{tabular}{|c|c|c|c|c|}
\hline \multirow[t]{2}{*}{ Protein } & \multirow[t]{2}{*}{ НАBР } & \multicolumn{3}{|c|}{ Kinetics assays (HeLa cells) } \\
\hline & & $K_{d}$ & $n_{\mathrm{H}}$ & BSC \\
\hline SIAP- & 34874 & 1000 & 1.3 & 903,500 \\
\hline \multirow[t]{4}{*}{1} & 34885 & 900 & 1.4 & $1,700,500$ \\
\hline & 34898 & 2900 & 1.6 & $3,500,400$ \\
\hline & 34901 & 1800 & 1.8 & $1,555,900$ \\
\hline & 34882 & \multicolumn{3}{|c|}{ Unsaturated } \\
\hline SIAP-2 & 36879 & 4500 & 1.9 & $4,500,000$ \\
\hline \multirow[t]{2}{*}{ Protein } & \multirow[t]{2}{*}{ НАBP } & \multicolumn{3}{|c|}{ Kinetics assays (HepG2 cells) } \\
\hline & & $K_{d}$ & $n_{\mathrm{H}}$ & BSC \\
\hline \multirow{3}{*}{$\begin{array}{l}\text { SIAP- } \\
1\end{array}$} & 34882 & 3000 & 1.4 & $2,600,000$ \\
\hline & 34874 & 2000 & 1.3 & $3,380,000$ \\
\hline & 34898 & 2900 & 1.3 & $2,600,500$ \\
\hline SIAP-2 & 36879 & 3400 & 2 & $3,500,000$ \\
\hline
\end{tabular}

and 34916 ( ${ }^{881}$ SSKPANEYHDGETIVSLSFN ${ }^{900}$ ) displayed specific binding activity for both host cell lines (Fig. 1).

SIAP-2 had 4 HepG2 HABPs, 36874 ( ${ }^{81}$ VKNNSDLTRSTNIDHPSPSS $\left.^{100}\right), \quad 36876 \quad\left({ }^{121}\right.$ KKEMNNKLEQQTNQNNNTIH $\left.^{140} Y\right)$, 36878 (161 LKNQDSSNSLISTNSNTMDE $\left.{ }^{180} Y\right)$ and 36879 ( ${ }^{181}$ LLLYSTNSEDNLDISFGELQ $\left.^{200}\right)$, and 2 HeLa HABPs, 36872 $\left({ }^{41}\right.$ TNTLKKNNSNNNNTNDIFGL ${ }^{60} Y$ ) and 36879, mainly located toward this protein's mid region. Only SIAP-2 HABP 36879 showed high affinity interaction with both cell lines. SIAP-1 and -2 HABPs had dissociation constants $\left(K_{d}\right)$ in the submicromolar range (900-3400) when tested in kinetic assays and had 900,000-3,500,000 binding sites per cell (BSC). All HABPs exhibited Hill coefficients $\left(n_{\mathrm{H}}\right)$ greater than 1 , showing a clear trend toward second ligand binding (positive cooperativity) (Table 1). SIAP-1derived HABP 34882 could not be saturated in the HeLa cell assay experimental conditions used here (Table 1 ), suggesting that this HABP could bind specifically to a larger number of receptor copies or to different receptor sites ( 2 or more binding sites); therefore, its saturation was not in line with a 1:1 interaction model (i.e. a completely different pattern to that found for the other HABPs evaluated here).

SIAP-1 and SIAP-2 participation in HeLa cell traversal and hepatocyte invasion has been demonstrated by Siau et al. [34]. The HABPs identified here thus correspond to protein specific regions recognizing and binding to cell surface receptors representing attractive targets for blocking parasite-host interactions. Interestingly, some SIAP-1 and SIAP-2 HABPs have shown high binding affinity to both cell lines thereby highlighting their potential importance as multi-event antimalarial targets (i.e. cell traversal and host cell invasion).

\subsection{SIAP-1 and -2 HABPs preferentially bind to chondroitin sulfate in both cell lines}

To date, two major proteins have been identified and thoroughly studied in sporozoites, interacting with different Kupffer and HepG2 cell receptors, mostly with glycoaminoglycans (GAGs) and heparin sulfate proteoglycans (HSPGs). The nature of the receptor involved in HABP binding to HeLa and HepG2 cells was determined by pre-treating cells with heparinase I (HI) and heparinase II (HII) acting on heparin-like oligosaccharides having high or low sulfate group content, respectively; chondroitinase AC (CAC) has also been seen to cleave chondroitin-6-sulfate, chondroitin-4sulfate and chondroitin-4,6-sulfate and chondroitinase $A B C$ (CABC) to cleave chondroitin-containing molecules plus dermatan sulfate.

When HeLa cells were treated with CAC and CABC enzymes, HABP 34874 binding became reduced by $45 \%$ and $66 \%$, respectively, 
Table 2

The effect of treating HepG2 and HeLa cells with enzymes on SIAP-1 and -2 HABP specific binding.

\begin{tabular}{|c|c|c|c|c|c|}
\hline HABPs & Control & $\mathrm{H} 1$ & $\mathrm{H} 2$ & CAC & CABC \\
\hline \multicolumn{6}{|c|}{ \% specific binding (HeLa cells) } \\
\hline 34874 & 100 & 76 & 244 & 55 & 34 \\
\hline 34882 & 100 & 182 & 133 & 171 & 136 \\
\hline 34898 & 100 & 84 & 96 & 134 & 18 \\
\hline 34916 & 100 & 97 & 102 & 116 & 54 \\
\hline 36879 & 100 & 66 & 61 & 198 & 31 \\
\hline \multicolumn{6}{|c|}{ \% specific binding (HepG2 cells) } \\
\hline 34874 & 100 & 40 & 66 & 100 & 41 \\
\hline 34882 & 100 & 97 & 142 & 100 & 0 \\
\hline 34898 & 100 & 143 & 100 & 216 & 0 \\
\hline 34916 & 100 & 70 & 70 & 136 & 96 \\
\hline 36879 & 100 & 55 & 84 & 100 & 28 \\
\hline
\end{tabular}

Standard deviations were below $5 \%$.

while this peptide's specific biding became reduced to $60 \%$ for $\mathrm{HI}$ and CABC-treated HepG2 cells and to $34 \%$ in the presence of HII. This data suggested that this HABP bound preferably to chondroitin sulfate on HeLa cells and to a combination of heparin-like sulfate on HepG2 cells (Table 2), similar to that observed for CSP on primary stellate cells [30]. HABPs 34898 and 34916 bound to chondroitin sulfate on HeLa cells due to CABC enzyme treatment reducing their specific binding to $82 \%$ and $46 \%$, respectively. Similar results were obtained with peptide 34898 and HepG2 cells, suggesting that this peptide interacted with similar receptor sites on both types of cell (Table 2). On the contrary, HABP 34916 binding became slightly reduced when HepG2 cells were treated with $\mathrm{HI}$ and HII. All the above data has shown that, similarly to that reported for CSP and TRAP, SIAP-1 contains regions responsible for recognizing different proteoglycans available on cell surface (HepG2 and HeLa) thereby allowing the parasite to transverse Kupffer cells and invade hepatocytes.

Specific binding percentages some enzyme-treated cells were higher than those obtained for untreated cells (both in HeLa and HepG2 lines) with enzymes such as CAC (Table 2). This suggested that host membrane modification by enzymes could lead to proteins becoming exposed (also called cryptic sequences or determinants) thereby increasing interaction with host cells (i.e. as in merozoite invasion of RBC). For example, AMA-1 expressed in $P$. falciparum sporozoites and merozoites micronemes binds to a putative membrane receptor known as "Kx", which is exposed on RBC surface after modification by trypsin-like enzymes [21]. Other merozoite-exposed proteins like PfRhopH3 have shown that binding to RBC surface is favored after enzyme treatment with trypsin, chymotrypsin or neuraminidase, suggesting interactions with proteins such as band 4.9, 4.1, ankyrin, and other internal membrane proteins [29].

HABP 36879 specific binding to HeLa cells became reduced by $69 \%$ in the presence of the CABC enzyme and by around $40 \%$ when HeLa cells were treated with HI and HII. Similar results were obtained when HepG2 cells were treated with $\mathrm{HI}$ and CABC (Table 2) suggesting that HABP 36879 predominantly recognized chondroitin sulfate, similar to that found with CSP on Kupffer cells.

SIAP-1 and -2 protein-derived HABP interaction with heparin and chondroitin sulfated glycoproteins on HeLa and HepG2 cell membranes could partly explain the experimental difficulties encountered in crosslinking when using bis(sulfosuccinimidyl) suberate $\left(\mathrm{BS}^{3}\right)$ with radiolabeled HABPs and membranes from each assessed cell (data not shown).

\subsection{SIAP-1 and SIAP-2 HABPs' structural features}

Previous studies have shown the structure-immunogenic potential relationship for several merozoite and sporozoite HABPs, highlighting the relevance of a deep knowledge of HABP structure for designing an improved synthetic $P$. falciparum vaccine $[2,4,27]$. Accordingly, SIAP-1 and SIAP-2 HABP secondary structure has been analyzed by $\mathrm{CD}$ and data deconvolution. The presence of $\alpha$-helical components on SIAP HABPs was revealed by the presence of characteristic minima at 206 and $222 \mathrm{~nm}$ with some displacements (Fig. 2, top), possibly related to the presence of $\beta$-turn and/or random coil elements, this being more notable for HABPs 34882, 34891 (Fig. 2, top) and 34914 spectra (data not shown). SELCON, CONTINLL and CDSTR analyses confirmed these observations, revealing 75-90\% $\alpha$ helical features for most SIAP-1 HABP structures, whereas HABPs 34891, 34882 and 34914 mostly had an unordered structure.

Similarly, SIAP-2 protein-derived HABPs 36876 and $36878 \mathrm{sec}-$ ondary structure spectra had minima at 205 and $222 \mathrm{~nm}$, these being characteristic of $\alpha$-helical elements (Fig. 2, bottom) thereby coinciding with analysis using deconvolution software where around $70 \%$ helical of structures were found, while HABP 36874 just contained $10 \%$ of structural elements (data not shown).

The structural analysis of CSP- and TRAP-derived peptides, as well as the sporozoite and liver stage antigen (SALSA) and the liver stage antigen-1 (LSA-1) [2,5,27], also revealed the presence of these structural elements which were directly related to the formation of a stable HLA-peptide-T-cell receptor conjugate once these HABPs' sequences had been specifically modified to induce a protective immune response in Aotus monkeys.

\subsection{Native SIAP is recognized in sporozoites}

Anti-SIAP antibodies were produced in mice immunized with synthetic peptides predicted to be B-cell epitopes to assess SIAP1 and -2 immunogenic ability. Immunofluorescence analysis of $P$. falciparum sporozoites revealed a strongly dotted pattern which extended to the sporozoite surface, suggesting that SIAPs were located in the micronemes and became translocated to the surface (Fig. 2). This was similar to previous reports [34], suggesting these proteins' important role during host cell invasion, according to their location on cell surface.

\subsection{Evaluating polymorphism in SIAP-1 and -2 HABPS}

Designing an antimalarial vaccine has been hampered by the high polymorphism found in Plasmodium proteins, particularly in those found to be exposed to the immune system such as those expressed on parasite surface or translocated to the surface from the apical organelles. High polymorphism has been found in genes encoding CSP, TRAP, merozoite surface protein (MSP) -1 and -2 , etc. [10].

It has been found that some HABPs are conserved and that, differently to polymorphic regions, they cannot induce an immune response which has been called "immunological silence". Thorough studies aimed at overcoming such hurdle have managed to decipher the rules intended to break such code of silence and efficiently activate a protection-inducing response against experimental challenge in the Aotus spp. animal model [28].

The polymorphism of SIAP-1 and SIAP-2 regions containing HABPs in FCB-2 (Colombian), PAS-2 (unknown origin) and FVO (Vietnamese) strains were analyzed based on the above findings. 929, 972, 949 and 700 bp bands were detected with the respective primer combinations described in Section 2 coinciding with each region's expected molecular weights. Control primers amplified a single 438 bp band (Supplementary material). SIAP-1 nucleotide and amino acid sequences from the three $P$. falciparum strains mentioned above were aligned with those from 3D7 (airport isolate found in the Netherlands), IGH-CR14 and RAJ116 (isolated in India), Dd2 (derived from the W2-mef strain isolated in Indochina) and HB3 (isolated in Honduras) strains, while SIAP-2 sequences were 
a

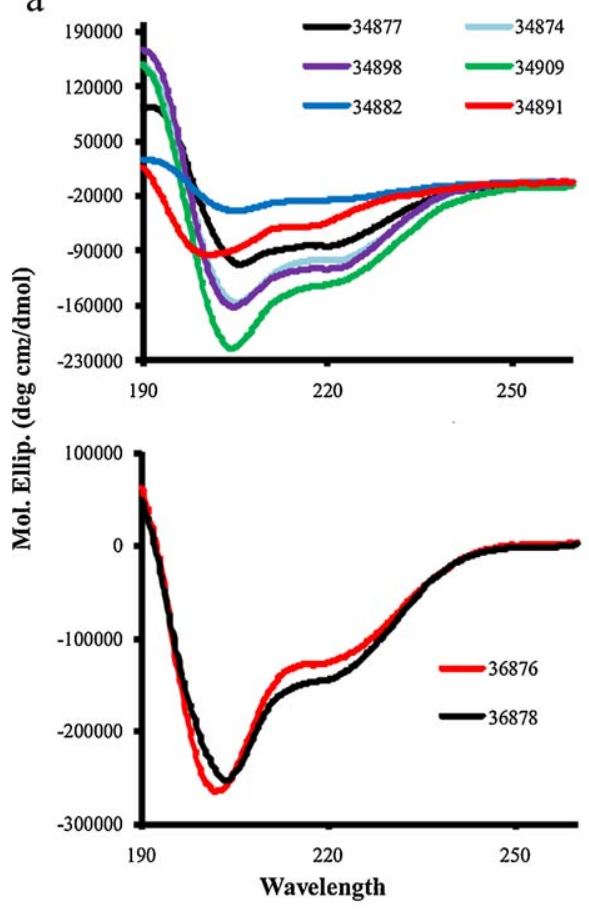

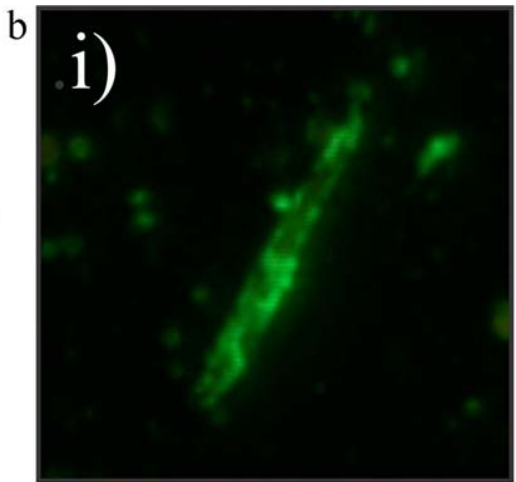

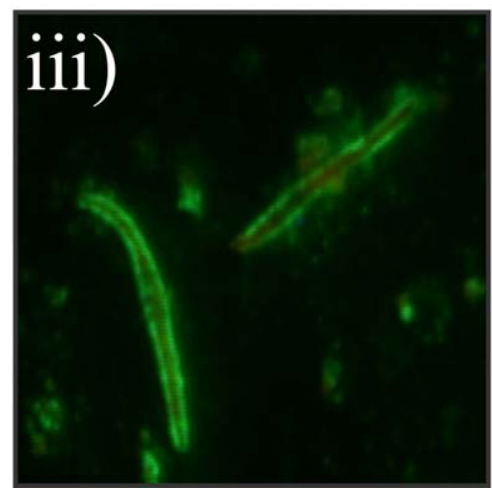

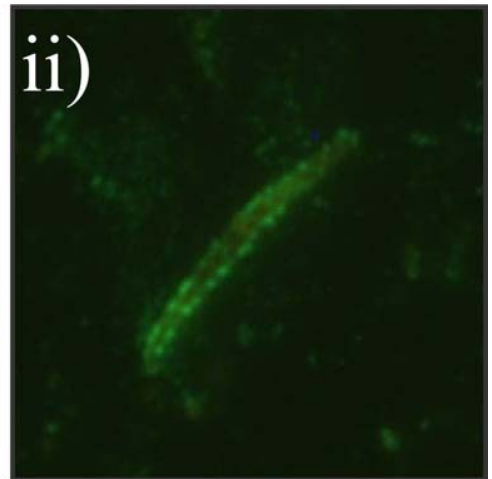

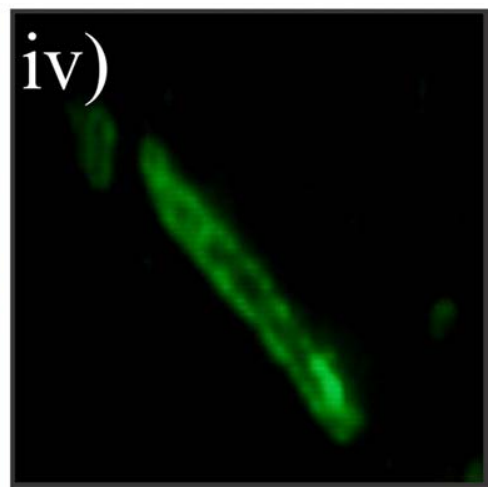

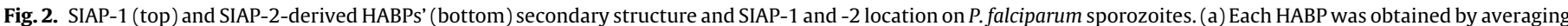

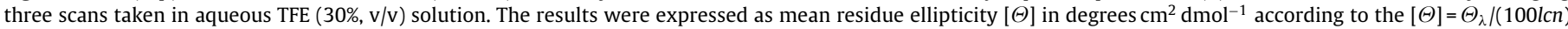

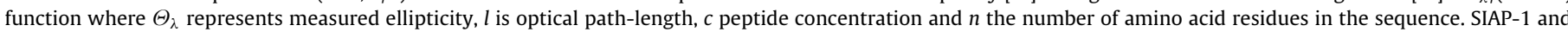

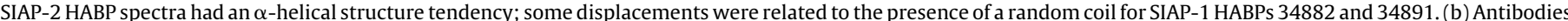
against SIAP-1 (i and ii) and SIAP-2 (iii and iv) proteins strongly recognized proteins, showing a dotted peripheral pattern which is characteristic of surface proteins.

Table 3

Evaluating the polymorphism of each SIAP-1 and -2 HABPs in P. falciparum strains.

\begin{tabular}{|c|c|c|c|c|c|c|}
\hline & HABPs & Nucleotide position & Substitution & Amino acid position & Substitution & Strain \\
\hline \multirow{8}{*}{ SIAP-1 } & 34882 & 655 & $\mathrm{~T}-\mathrm{A}$ & 219 & $\mathrm{~L}-\mathrm{I}$ & FCB2-FVO-PAS2 \\
\hline & 34883 & 667 & $A-T$ & 223 & $N-Y$ & FCB2-FVO-PAS2 \\
\hline & & 671 & $G-A$ & 224 & $\mathrm{~S}-\mathrm{N}$ & IGH-CR14-RAJ116-Dd2-HB3-FCB2-FVO-PAS2 \\
\hline & 34885 & 819 & $G-A$ & 273 & $\mathrm{M}-\mathrm{I}$ & RAJ116-Dd2-HB3-FCB2-FVO-PAS2 \\
\hline & 34891 & 1171 & $\mathrm{~T}-\mathrm{C}$ & 391 & $S-P$ & IGH-CR14-RAJ116-Dd2-HB3-FCB2-FVO-PAS2 \\
\hline & & 1180 & $A-G$ & 394 & $\mathrm{~N}-\mathrm{D}$ & HB3 \\
\hline & 34901 & 1756 & $G-A$ & 586 & V - I & IGH-CR14 \\
\hline & & 1757 & $\mathrm{~T}-\mathrm{C}$ & 586 & $\mathrm{~V}-\mathrm{A}$ & HB3 \\
\hline \multirow{2}{*}{ SIAP-2 } & 36872 & 122 & $\mathrm{C}-\mathrm{A}$ & 41 & $\mathrm{~T}-\mathrm{K}$ & PAS2 \\
\hline & 36874 & 283 & $\mathrm{C}-\mathrm{T}$ & 95 & $\mathrm{H}-\mathrm{Y}$ & FCB2-FVO-PAS2 \\
\hline
\end{tabular}

compared to 3D7, IGH-CR14 and RAJ116 strains. Clustal W software was used for making all alignments (Supplementary material) [6]. Table 3 shows strain-specific polymorphisms in HABP regions and their position was numbered according to the 3D7 reference strain. SIAP-1-derived HABPs 34882, 34883, 34891 and 34901 (from the 20 identified) and SIAP-2-derived HABPs 36872 and 36874 had polymorphisms in their amino acid sequences thereby hampering their inclusion in future immunological studies in the Aotus spp. model (manuscript in preparation).

SIAP-1 HABPs 34874, 34877, 34879, 34888, 34893, 34898, 34899, 34904, 34907, 34909, 34911, 34912, 34914 and 34916 and SIAP-2 HABPs 36876, 36878 and 36879 had 100\% amino acid sequence identity in the different $P$. falciparum strains studied. No non-synonymous substitutions were observed in nucleotide sequences (data not shown). These results showed that most HABPs identified in both SIAPs were highly conserved in strains from different geographical parts of the world.

These peptides together with some others derived from different $P$. falciparum sporozoite proteins such as CSP [12], TRAP
[12], LSA-3 [11], SPECT-1 and SPECT-2 [25] could be included, when properly modified [26] as potential components of a minimal subunit based chemically synthesized fully effective anti-malarial vaccine.

\section{Conclusions}

This work has presented the fine mapping of sporozoite invasion-associated SIAP-1 and SIAP-2 which led to identifying specific binding regions in each protein interacting with HepG2 and HeLa cells. Most SIAP-1 and -2-derived HABPs displayed $\alpha$-helical structural elements, their amino acid sequences are conserved in different $P$. falciparum strains and have a high affinity to chondroitin sulfate and heparin sulfate-type receptors on HepG2 and HeLa cell surface (similar to what has been reported for CSP and/or TRAP). All the above data, along with SIAP-1 and -2 immunogenicity and location on sporozoite membrane, strongly supports including conserved HABPs as potential components of a new 
generation of minimal subunit-based, multistage, multi-antigen, chemically produced vaccines against the most lethal form of malaria.

\section{Acknowledgement}

We would like to thank Jason Garry for translating this manuscript.

\section{Appendix A. Supplementary data}

Supplementary data associated with this article can be found, in the online version, at doi:10.1016/j.peptides.2011.08.008.

\section{References}

[1] Akhouri RR, Sharma A, Malhotra P, Sharma A. Role of Plasmodium falciparum thrombospondin-related anonymous protein in host-cell interactions. Malar J 2008; 7:63.

[2] Bermudez A, Vanegas M, Patarroyo ME. Structural and immunological analysis of circumsporozoite protein peptides: a further step in the identification of potential components of a minimal subunit-based, chemically synthesised antimalarial vaccine. Vaccine 2008;26:6908-18.

[3] Bongfen SE, Ntsama PM, Offner S, Smith T, Felger I, Tanner M, et al. The N-terminal domain of Plasmodium falciparum circumsporozoite protein represents a target of protective immunity. Vaccine 2009;27:328-35.

[4] Cifuentes G, Bermudez A, Rodriguez R, Patarroyo MA, Patarroyo ME. Shifting the polarity of some critical residues in malarial peptides' binding to host cells is a key factor in breaking conserved antigens' code of silence. Med Chem 2008;4:278-92.

[5] Cifuentes G, Vanegas M, Martinez NL, Pirajan C, Patarroyo ME. Structural characteristics of immunogenic liver-stage antigens derived from $P$. falciparum malarial proteins. Biochem Biophys Res Commun 2009;384:455-60.

[6] Combet C, Blanchet C, Geourjon C, Deleage G. NPS@: network protein sequence analysis. Trends Biochem Sci 2000;25:147-50.

[7] Curtidor H, Arevalo G, Vanegas M, Vizcaino C, Patarroyo MA, Forero M, et al. Characterization of Plasmodium falciparum integral membrane protein Pf25-IMP and identification of its red blood cell binding sequences inhibiting merozoite invasion in vitro. Protein Sci 2008;17:1494-504.

[8] Curtidor H, Garcia J, Vanegas M, Puentes F, Forero M, Patarroyo ME. Identification of peptides with high red blood cell and hepatocyte binding activity in the Plasmodium falciparum multi-stage invasion proteins: PfSPATR and MCP-1. Biochimie 2008;90:1750-9.

[9] Engelmann S, Silvie O, Matuschewski K. Disruption of Plasmodium sporozoite transmission by depletion of the Sporozoite Invasion-Associated Protein-1. Eukaryot Cell 2009.

[10] Escalante AA, Lal AA, Ayala FJ. Genetic polymorphism and natural selection in the malaria parasite Plasmodium falciparum. Genetics 1998;149:189-202.

[11] Garcia JE, Curtidor H, Lopez R, Rodriguez L, Vera R, Valbuena J, et al. Liver stage antigen 3 Plasmodium falciparum peptides specifically interacting with HepG2 cells. J Mol Med 2004;82:600-11.

[12] Garcia JE, Puentes A, Patarroyo ME. Developmental biology of sporozoite-host interactions in Plasmodium falciparum malaria: implications for vaccine design. Clin Microbiol Rev 2006;19:686-707.

[13] Houghten RA. General method for the rapid solid-phase synthesis of large numbers of peptides: specificity of antigen-antibody interaction at the level of individual amino acids. Proc Natl Acad Sci U S A 1985;82:5131-5.

[14] Ishino T, Chinzei Y, Yuda M. A Plasmodium sporozoite protein with a membrane attack complex domain is required for breaching the liver sinusoidal cell layer prior to hepatocyte infection. Cell Microbiol 2005;7:199-208.

[15] Ishino T, Chinzei Y, Yuda M. Two proteins with 6-cys motifs are required for malarial parasites to commit to infection of the hepatocyte. Mol Microbiol 2005;58:1264-75.

[16] Ishino T, Yano K, Chinzei Y, Yuda M. Cell-passage activity is required for the malarial parasite to cross the liver sinusoidal cell layer. PLoS Biol 2004;2:E4.
[17] Kaiser K, Camargo N, Coppens I, Morrisey JM, Vaidya AB, Kappe SH. A member of a conserved Plasmodium protein family with membrane-attack complex/perforin (MACPF)-like domains localizes to the micronemes of sporozoites. Mol Biochem Parasitol 2004:133:15-26.

[18] Kaiser K, Matuschewski K, Camargo N, Ross J, Kappe SH. Differential transcriptome profiling identifies Plasmodium genes encoding pre-erythrocytic stage-specific proteins. Mol Microbiol 2004;51:1221-32.

[19] Kappe SH, Buscaglia CA, Nussenzweig V. Plasmodium sporozoite molecular cell biology. Annu Rev Cell Dev Biol 2004;20:29-59.

[20] Kariu T, Ishino T, Yano K, Chinzei Y, Yuda M. CelTOS, a novel malarial protein that mediates transmission to mosquito and vertebrate hosts. Mol Microbiol 2006;59:1369-79.

[21] Kato K, Mayer DC, Singh S, Reid M, Miller LH. Domain III of Plasmodium falciparum apical membrane antigen 1 binds to the erythrocyte membrane protein Kx. Proc Natl Acad Sci U S A 2005;102:5552-7.

[22] Labaied M, Camargo N, Kappe SH. Depletion of the Plasmodium berghe thrombospondin-related sporozoite protein reveals a role in host cell entry by sporozoites. Mol Biochem Parasitol 2007;153:158-66.

[23] Lopez R, Curtidor H, Urquiza M, Garcia J, Puentes A, Suarez J, et al. Plasmodium falciparum: binding studies of peptide derived from the sporozoite surface protein 2 to Hep G2 cells. J Pept Res 2001;58:285-92.

[24] Moreira CK, Templeton TJ, Lavazec C, Hayward RE, Hobbs CV, Kroeze H, et al. The Plasmodium TRAP/MIC2 family member TRAP-Like Protein (TLP), is involved in tissue traversal by sporozoites. Cell Microbiol 2008;10:1505-16.

[25] Patarroyo ME, Alba MP, Curtidor H. Biological and structural characteristics of the binding peptides from the sporozoite proteins essential for cell traversal (SPECT)-1 and -2. Peptides 2011;32:154-60.

[26] Patarroyo ME, Bermudez A, Patarroyo MA. Structural and immunological principles leading to chemically synthesized, multiantigenic, multistage, minimal subunit-based vaccine development. Chem Rev 2011;111:3459-507.

[27] Patarroyo ME, Cifuentes G, Rodriguez R. Structural characterisation of sporozoite components for a multistage, multi-epitope, anti-malarial vaccine. Int J Biochem Cell Biol 2008;40:543-57.

[28] Patarroyo ME, Patarroyo MA. Emerging rules for subunit-based, multiantigenic multistage chemically synthesized vaccines. Acc Chem Res 2008;41:377-86.

[29] Pinzon CG, Curtidor H, Reyes C, Mendez D, Patarroyo ME. Identification of Plasmodium falciparum RhopH3 protein peptides that specifically bind to erythrocytes and inhibit merozoite invasion. Protein Sci 2008;17:1719-30.

[30] Pradel G, Garapaty S, Frevert U. Proteoglycans mediate malaria sporozoite targeting to the liver. Mol Microbiol 2002;45:637-51.

[31] Rathore D, Hrstka SC, Sacci Jr JB, De la Vega P, Linhardt RJ, Kumar S, et al. Molecular mechanism of host specificity in Plasmodium falciparum infection: role of circumsporozoite protein. J Biol Chem 2003;278:40905-10.

[32] Rodriguez LE, Curtidor H, Urquiza M, Cifuentes G, Reyes C, Patarroyo ME. Intimate molecular interactions of $P$. falciparum merozoite proteins involved in invasion of red blood cells and their implications for vaccine design. Chem Rev 2008;108:3656-705

[33] Rodriguez LE, Urquiza M, Ocampo M, Suarez J, Curtidor H, Guzman F, et al. Plasmodium falciparum EBA-175 kDa protein peptides which bind to human red blood cells. Parasitology 2000;120(Pt 3):225-35.

[34] Siau A, Silvie O, Franetich JF, Yalaoui S, Marinach C, Hannoun L, et al. Temperature shift and host cell contact up-regulate sporozoite expression of Plasmodium falciparum genes involved in hepatocyte infection. PLoS Pathog 2008;4:e1000121.

[35] Silvie O, Franetich JF, Charrin S, Mueller MS, Siau A, Bodescot M, et al. A role for apical membrane antigen 1 during invasion of hepatocytes by Plasmodium falciparum sporozoites. J Biol Chem 2004;279:9490-6.

[36] Sinnis P, Coppi A. A long and winding road: the Plasmodium sporozoite's journey in the mammalian host. Parasitol Int 2007;56:171-8.

[37] Sreerama N, Woody RW. Estimation of protein secondary structure from circular dichroism spectra: comparison of CONTIN, SELCON, and CDSSTR methods with an expanded reference set. Anal Biochem 2000;287:252-60.

[38] Trager W, Jenson JB. Cultivation of malarial parasites. Nature 1978;273:621-2.

[39] Valbuena J, Rodriguez L, Vera R, Puentes A, Curtidor H, Cortes J, et al. Synthetic peptides from Plasmodium falciparum apical membrane antigen 1 (AMA-1) specifically interacting with human hepatocytes. Biochimie 2006;88:1447-55.

[40] van Dijk MR, Douradinha B, Franke-Fayard B, Heussler V, van Dooren MW, van Schaijk B, et al. Genetically attenuated P36p-deficient malarial sporozoites induce protective immunity and apoptosis of infected liver cells. Proc Natl Acad Sci U S A 2005;102:12194-9. 